\title{
Solar electricity via an Air Brayton cycle with an integrated two-step thermochemical cycle for heat storage based on $\mathrm{Co}_{3} \mathrm{O}_{4} / \mathrm{CoO}$ redox reactions: Thermodynamic analysis
}

\author{
Andrew J. Schrader ${ }^{1}$, Alexander P. Muroyama ${ }^{1}$, Peter G. Loutzenhiser ${ }^{1, *}$ \\ ${ }^{1}$ George W. Woodruff School of Mechanical Engineering, Georgia Institute of Technology, \\ Atlanta, Georgia USA, 30332-0405 \\ *Corresponding Author: Peter G. Loutzenhiser, Email: peter.loutzenhiser@me.gatech.edu, \\ Phone: +1. 404.894.3012
}

\begin{abstract}
Solar electricity production is considered in an Air Brayton cycle with an integrated two-step thermochemical cycle for heat storage based on $\mathrm{Co}_{3} \mathrm{O}_{4} / \mathrm{CoO}$ redox reactions. The two steps of the heat storage cycle are encompassed by 1) the high-temperature thermolysis of $\mathrm{Co}_{3} \mathrm{O}_{4}$ to $\mathrm{CoO}$ and $\mathrm{O}_{2}$ under vacuum pressure utilizing concentrated solar irradiation for process heat; and 2) the highly exothermic re-oxidation of $\mathrm{CoO}$ with $\mathrm{O}_{2}$ at elevated pressures, resulting in $\mathrm{Co}_{3} \mathrm{O}_{4}$ and providing the heat input to the Air Brayton cycle. The two steps may be decoupled, enabling long-term storage of heat (i.e., thermochemical storage of sunlight). A thermodynamic analysis is applied to determine cycle efficiencies over a range of operating parameters, and an exergy analysis is used to identify the major sources of irreversibilities. A maximum cycle efficiency of $44 \%$ was determined for re-oxidizing the $\mathrm{CoO}$ at $30 \mathrm{bar}$, with the maximum cycle efficiency reducing to $26 \%$ for a decrease in pressure to 5 bar.
\end{abstract}

Keywords: Concentrated Solar Energy; Thermochemical Energy

Storage; Two - Step Thermochemical Cycle; Cobalt Oxide;

Thermodynamic Analysis 


\section{Introduction}

Sunlight is by far the most abundant energy resource available on earth. However, solar irradiation is relatively dilute and intermittent. Measures have been taken to overcome these obstacles in regions with abundant solar resources by concentrating solar irradiation and using the resulting heat to produce electricity [i.e., concentrated solar power (CSP)]. Solar concentrating facilities equipped with power towers with heliostat fields and parabolic dishes are capable of achieving solar concentrations in excess of 1000 suns $\left(1\right.$ sun $\left.=1 \mathrm{~kW} / \mathrm{m}^{2}\right)$. Major challenges to current CSP systems are effectively storing intermittent sunlight and operating at high temperatures, directly translating to higher efficiencies. Increasing CSP heat storage capabilities offers a renewable pathway forward towards significantly extending solar electricity production to periods when sunlight is unavailable. On-demand production greatly improves the value of CSP, and the economic competitiveness of CSP facilities is inherently tied to the capacity for energy storage (Pitz-Paal et al. 2012).

Three methods are currently employed to store solar heat: 1) sensible energy storage (SES), 2) latent energy storage (LES), and 3) thermochemical energy storage (TCES). SES systems store sensible energy using heat transfer fluids (e.g., oil, synthetic oil, molten salts, etc.). SES is commonly used for commercial CSP systems, but it affords numerous challenges due to high pressure components, cost of different heat transfer media, and temperature limitations that impede facility operations (Medrano et al. 2010). This is especially prevalent with molten salts (e.g., $\mathrm{NaNO}_{3}$ and $\mathrm{KNO}_{3}$ mixtures) that solidify below $200{ }^{\circ} \mathrm{C}$ and often degrade at temperatures greater than $600{ }^{\circ} \mathrm{C}$ (Medrano et al. 2010, Ho et al. 2014). Maintaining these temperatures is challenging, with the maximum temperature limiting the facility output work potential. An alternative SES system is a falling particle receiver, which utilizes a curtain of ceramic particles or proppants as a thermal storage medium. The particles are predicted to heat rapidly to temperatures greater than $600{ }^{\circ} \mathrm{C}$ and can be temporarily stored to retain sensible heat while remaining stable. The high temperature particles can be accessed on demand to supply process heat to the working fluid of a power cycle (Siegel and Kolb 2009, Ho et al. 2014).

CSP facilities with LES capability store heat in a phase change material (PCM) with a high heat of fusion. Heat is stored when a thermal gradient exists between the heat transfer fluid (HTF) and the PCM. A heat exchanger then transfers heat to the PCM, storing heat by driving the PCM 
phase change. Heat extraction occurs when solar conditions fluctuate and the HTF becomes cooler than the PCM, removing the heat from the material. Challenges to LES include the selection of a PCM and the large thermal resistance between the PCM and HTF. A favorable PCM must have high thermal conductivity and a constant charge/discharge temperature during phase change that is tailored to the working conditions of the CSP facility (Sharma et al. 2009, Liu et al. 2012). The low thermal conductivities of most PCMs require specialized storage / heat exchange units with a series of highly conductive fins to promote heat transfer (Steinmann et al. 2009). One of the most extensively studied PCMs includes $\mathrm{NaNO}_{3}$. Previous works have assessed the eutectic mixture of $\mathrm{NaNO}_{3} / \mathrm{KNO}_{3}$ in a $100 \mathrm{~kW}$ th latent heat storage system. The system successfully stored and extracted heat from the PCM, providing process heat to a Steam Rankine cycle despite low HTF temperatures (Bayón et al. 2010).

TCES systems utilize concentrated solar irradiation as process heat to drive reversible chemical reactions, enabling the storage of sunlight in a chemical form. Stored heat is extracted by running the reverse chemical reaction, releasing heat to drive power cycles. Previous work has resulted in an ammonia-based TCES able to deliver process heat at $475^{\circ} \mathrm{C}$ to a power cycle (Lovegrove et al. 1999). Alternative TCES studies include two-step solar thermochemical cycles based on metal oxide redox reactions (Bilgen et al. 1977, Fletcher 2000, Kodama 2003, Steinfeld 2005, Meier and Sattler 2009, Perkins and Weimer 2009, Loutzenhiser et al. 2010, Neises et al. 2012), with a range of redox pairs having been evaluated for both energy storage and extraction potential (Abanades et al. 2006, Wong 2011). Evaluations have encompassed both thermogravimetry and economic analyses for different metal oxides with the most promising redox pairs, including $\mathrm{BaO}_{2} / \mathrm{BaO}, \mathrm{Mn}_{2} \mathrm{O}_{3} / \mathrm{Mn}_{3} \mathrm{O}_{4}$, and $\mathrm{Co}_{3} \mathrm{O}_{4} / \mathrm{CoO}$ (Wong 2011). $\mathrm{Co}_{3} \mathrm{O}_{4} / \mathrm{CoO}$ redox reactions have been the focus of further TCES studies aimed at characterizing reaction parameters for complete and cyclic reduction and oxidation with particulate and monolithic structures (Agrafiotis et al. 2014, Pagkoura et al. 2014). Complete reduction and oxidation was demonstrated between $800-1000{ }^{\circ} \mathrm{C}$. The cycle was additionally demonstrated in a rotary kiln with directly irradiated $\mathrm{Co}_{3} \mathrm{O}_{4}$ particles followed by off- sun re-oxidation of the reduced particles in air (Neises et al. 2012). Partnering the high energy density with encouraging experimental results, $\mathrm{Co}_{3} \mathrm{O}_{4} / \mathrm{CoO}$ is an excellent redox pair for TCES. 
In the present work, an Air Brayton cycle is thermodynamically examined with an integrated two-step solar thermochemical cycle for heat storage based on $\mathrm{Co}_{3} \mathrm{O}_{4} / \mathrm{CoO}$ redox reactions. The first step is the thermolysis of $\mathrm{Co}_{3} \mathrm{O}_{4}$ using concentrated solar irradiation as process heat, represented as:

$$
\mathrm{Co}_{3} \mathrm{O}_{4} \rightarrow 3 \mathrm{CoO}+1 / 2 \mathrm{O}_{2} \quad \Delta H_{298.15 \mathrm{~K}}=196.2 \mathrm{~kJ} \cdot \mathrm{mol}^{-1}
$$

The particles can then be stored in an inert environment and re-oxidized in the reversible second step that does not require solar energy and releases heat, represented as:

$$
3 \mathrm{CoO}+1 / 2 \mathrm{O}_{2} \rightarrow \mathrm{Co}_{3} \mathrm{O}_{4} \quad \Delta H_{298.15 \mathrm{~K}}=-196.2 \mathrm{~kJ} \cdot \mathrm{mol}^{-1}
$$

$\mathrm{Co}_{3} \mathrm{O}_{4}$ is then recycled to the first step, completing the cycle. The steps of the cycle may be decoupled, enabling the long-term chemical storage of sunlight to provide the necessary heat inputs to the power cycles to produce on-demand electricity. This work builds on previous analyses that examined thermodynamic constraints for CSP facility operation and two-step solar thermochemical cycles based on metal oxide redox reactions for fuel production (Lovegrove et al. 1999, Sturzenegger and Nüesch 1999, Loutzenhiser and Steinfeld 2011, Xu et al. 2011, Mahfuz et al. 2014).

Ranges for reactor temperature and $\mathrm{O}_{2}$ partial pressure were determined thermodynamically to identify temperatures above which the $\mathrm{Co}_{3} \mathrm{O}_{4} \rightarrow 3 \mathrm{CoO}+1 / 2 \mathrm{O}_{2}$ reaction is spontaneous (i.e., $\Delta G \leq$ $0) . \Delta G$ is given as a function of temperature and $\mathrm{O}_{2}$ partial pressure in Figure 1. Three different $\mathrm{O}_{2}$ partial pressures were plotted to show the impact of $\mathrm{O}_{2}$ on the reaction. $\Delta G$ is positive at 800 $\mathrm{K}$ for $p_{\mathrm{O}_{2}}=0.001$ bar, indicative of a favorable back reaction, and decreases monotonically with increasing temperature until reaching $T=1093.0 \mathrm{~K}$, where the reaction becomes spontaneous. The same trend for $\Delta G$ is shown for both $p_{\mathrm{O}_{2}}=1$ bar and 6 bar where the reaction is shifted further to the right according to Le Chatalier's principle, resulting in equilibrium temperatures of $1252.8 \mathrm{~K}$ and $1351.8 \mathrm{~K}$ respectively, where the back reaction is favored.

\section{Thermodynamic analysis}

The Air Brayton cycle integrated with the two-step solar thermochemical heat storage cycle is schematically depicted in Figure 2 with relevant energy flows. Concentrated solar irradiation 
enters the solar thermochemical reactor through a quartz window and impinges directly upon $\mathrm{Co}_{3} \mathrm{O}_{4} / \mathrm{CoO}$ particles entering from a cold storage bin. Particles are heated rapidly to $T_{\text {reactor }}$ and undergo thermolyses to $\mathrm{O}_{2}$ and $\mathrm{CoO}$. The solar thermochemical reactor is maintained at a reduced pressure by a vacuum pump to ensure favorable thermodynamics and complete conversion for the $\mathrm{Co}_{3} \mathrm{O}_{4}$ thermolysis at lower temperatures. The $\mathrm{O}_{2}$ evolves from the particles and is continuously extracted from the cavity, driving a non-equilibrium process, cooled to ambient temperature, and removed through the vacuum pump. CoO particles are fed into a hot storage bin and then introduced to a re-oxidizer. $\mathrm{CoO}$ particles flow in the opposite direction to a pressurized air flow, entering the re-oxidizer from an air compressor. The entering air comes into contact with particles that are cooled by the upstream flow and partially reacted. The lower temperatures further drive the re-oxidation of the $\mathrm{CoO}$ particles to $\mathrm{Co}_{3} \mathrm{O}_{4}$ due to a favorable $3 \mathrm{CoO}+1 / 2 \mathrm{O}_{2}$ reaction at lower temperature as shown in Figure 1. This enables the air stream to extract both the sensible and reaction heat. An $\mathrm{O}_{2}$-depleted, pressurized air flow exits the reoxidizer at its maximum temperature and is expanded across a turbine to produce work. In actual practice, particle feeding to the re-oxidizer from the hot storage bin may be accomplished through a lock or screw-type feeder (Ermanoski et al. 2013) while a filter or similar component would prevent entrained particles from exiting the re-oxidizer and entering the turbine. $\mathrm{CoO}$ and/or $\mathrm{Co}_{3} \mathrm{O}_{4}$ particles exit the re-oxidizer depending on conversion and are stored in a cold bin until being re-introduced into the solar thermochemical reactor.

The thermodynamic analysis assumes a continuous, steady-state cycle to determine maximum theoretical efficiencies and identify major sources of irreversibility. In reality, the solar thermochemical reactor will be oversized compared to the re-oxidizer, enabling significant storage capacity of $\mathrm{CoO}$ during periods when sunlight is unavailable. The work required to transport the particles and overcome pressure losses throughout the system were neglected along with kinetic and potential energies. Thermophysical properties were extracted from HSC. The analysis was normalized to $3 \mathrm{~mol} / \mathrm{s}$ of $\mathrm{CoO}$ exiting the solar thermochemical reactor. Steady flow rates of particles are assumed to pass between the solar thermochemical reactor and the reoxidizer in the analysis. The environmental temperature and pressure (i.e., the dead state) were $T_{0}=298.15 \mathrm{~K}$ and $p_{0}=1 \mathrm{bar}$, respectively, and the molar fractions of $\mathrm{N}_{2}$ and $\mathrm{O}_{2}$ in air were assumed as $y_{\mathrm{N}_{2,0}}=0.79$ and $y_{\mathrm{O}_{2,0}}=0.21$, respectively (Moran and Shapiro 2000). Ideal gas and solution behaviors were assumed for gases and solids, respectively. 
The $\mathrm{CoO}$ particles leaving the solar thermochemical reactor at $T_{\text {reactor }}$ are deposited in a wellinsulated and reversible hot storage bin. The particles enter the re-oxidizer and flow in the opposite direction of a stream of pressurized air introduced from an air compressor. Air from the environment composed of $\mathrm{O}_{2}$ and $\mathrm{N}_{2}$ is isentropically compressed to fixed pressure. The rate of work into the compressor is given as:

$$
\dot{W}_{\text {comp }}=\left.\dot{n}_{\text {air }} \Delta H\right|_{y_{\mathrm{O}_{2}, 0} \mathrm{O}_{2}, y_{\mathrm{N}_{2}, 0} \mathrm{~N}_{2}} \text { at } T_{0} \rightarrow T_{\text {comp }}
$$

where $\Delta H$ is the total enthalpy change and $\dot{n}$ is the molar flow rates. Hot CoO particles are introduced at one end of the re-oxidizer at $T_{\text {reactor }}$ and move in a counter flow to a pressurized air stream. Operation at increased $\mathrm{O}_{2}$ partial pressures enables airflow temperatures greater than $T_{\text {reactor }}$ to occur at the turbine due to favorable thermodynamics at higher temperatures according to Le Chatelier's principle as shown in Figure 1. The direct contact heat exchanger allows the $\mathrm{O}_{2}$ to react with the $\mathrm{CoO}$ particles, recovering both sensible and reaction heat. The maximum turbine inlet temperature, $T_{\text {turbine,max }}$, was determined by calculating the temperature for $\Delta G=0$ for $3 \mathrm{CoO} \rightarrow \mathrm{Co}_{3} \mathrm{O}_{4}+1 / 2 \mathrm{O}_{2}$ using the partial pressure of $\mathrm{O}_{2}$ of the air stream exiting the reoxidizer. Air flow temperatures greater than $T_{\text {turbine,max }}$ are not thermodynamically favored as the reaction is no longer spontaneous. $T_{\text {turbine }}$ is assumed equivalent to $T_{\text {turbine,max }}$ if supported by an energy balance across the re-oxidizer. The minimum temperature of the exiting particle stream, $T_{\text {recover,min }}$ was equal to $T_{\text {comp. }}$. Chemical equilibrium between the incoming air stream and the exiting particle stream was employed in addition to an energy balance across the re-oxidizer to determine $T_{\text {recover }}$ and the conversion extent of $\mathrm{CoO}$ to $\mathrm{Co}_{3} \mathrm{O}_{4}$ at the particle outlet. The reoxidizer was assumed to be well-insulated and the particles and fluid were assumed to be in local thermal equilibrium at both the particle inlet and outlet. Air entering the re-oxidizer is assumed to heat rapidly to $T_{\text {recover. }} T_{\text {recover }}$ and $T_{\text {turbine }}$ were determined by applying the described thermodynamic constraints bounding the temperatures and applying an energy balance, given as:

$$
\begin{aligned}
& 0=\left.\dot{n}_{\mathrm{Co}_{3} \mathrm{O}_{4}, \text { recover }} \Delta H\right|_{3 \mathrm{CoO} \text { at } T_{\text {reactor }}+\frac{1}{2} \mathrm{O}_{2} \text { at } T_{\text {comp }} \rightarrow \mathrm{Co}_{3} \mathrm{O}_{4} \text { at } T_{\text {recover }}}+ \\
& \left.\dot{n}_{\text {CoO,recover }} \Delta H\right|_{\mathrm{CoO} \text { at } T_{\text {reactor }} \rightarrow T_{\text {recover }}}+\left.\left(\dot{n}_{\text {air }}-\frac{1}{2} \dot{n}_{\mathrm{CO}_{3} \mathrm{O}_{4}, \text { recover }}\right) \Delta H\right|_{y_{\mathrm{O}_{2}, \text { turbine }} \mathrm{O}_{2}, y_{\mathrm{N}_{2}, \text { turbine }} \mathrm{N}_{2} \text { at } T_{\text {comp }} \rightarrow T_{\text {turbine }}}
\end{aligned}
$$

$T_{\text {recover }}$ and $T_{\text {turbine }}$ were solved iteratively with convergence criteria of $<0.1 \mathrm{~K}$ for both temperatures and the $\mathrm{CoO}$ and $\mathrm{Co}_{3} \mathrm{O}_{4}$ fractions at the outlet with a convergence criterion of < $10^{-4} . T_{\text {turbine }}$ was verified within a turbine operation range with temperatures $(1000-1600 \mathrm{~K})$ and 
pressures (5-30 bars) as specified in (Hischier et al. 2012). The conversion extent of CoO to $\mathrm{Co}_{3} \mathrm{O}_{4}$ in the flow is given as:

$$
X=\frac{3 \dot{n}_{\mathrm{Co}_{3} \mathrm{O}_{4} \text {,ecover }}}{\dot{n}_{\mathrm{CoO}, \text { reactor }}}
$$

The re-oxidizer was provided excess $\mathrm{O}_{2}$ for all cases considered, thus $X$ is dependent upon equilibrium conditions and the energy balance across the re-oxidizer. The rate of exergy destruction across the re-oxidizer was used to assess performance, given as:

$$
\begin{aligned}
& \dot{\Xi}_{\text {D,re-oxidizer }}=\left.\dot{n}_{\mathrm{CO}_{3} \mathrm{O}_{4}, \text { recover }} \Delta \Xi_{\mathrm{f}}\right|_{3 \mathrm{CoO} \text { at } T_{\text {reactor }}+\frac{1}{2} \mathrm{O}_{2} \text { at } T_{\text {comp }} \rightarrow \mathrm{Co}_{3} \mathrm{O}_{4} \text { at } T_{\text {recover }}}+ \\
& \left.\dot{n}_{\mathrm{CoO}, \text { recover }} \Delta \Xi_{\mathrm{f}}\right|_{\mathrm{CoO} \text { at } T_{\text {reactor }} \rightarrow T_{\text {recover }}}+\left.\left(\dot{n}_{\text {air }}-\frac{1}{2} \dot{n}_{\mathrm{Co}_{3} \mathrm{O}_{4}, \text { recover }}\right) \Delta \Xi_{\mathrm{f}}\right|_{y_{\mathrm{O}_{2}, \text { turbine }} \mathrm{O}_{2}, y_{\mathrm{N}_{2}, \text { turbine }} \mathrm{N}_{2} \text { at } p_{\text {comp }}, T_{\text {comp }} \rightarrow p_{\text {comp }}, T_{\text {turbine }}}
\end{aligned}
$$

where $\Delta \Xi_{\mathrm{f}}$ is the change in exergy flow (both mechanical and chemical). The particles exiting the re-oxidizer enter the well-insulated cold storage bin. The $\mathrm{O}_{2}$ depleted air exiting the reoxidizer is fed directly into the turbine. Expansion across the turbine to $p_{0}$ was assumed isentropic, and the rate of work across the turbine is given as:

$$
\dot{W}_{\text {turbine }}=\left.\left(\dot{n}_{\text {air }}-\frac{1}{2} \dot{n}_{\mathrm{Co}_{3} \mathrm{O}_{4}, \text { recover }}\right) \Delta H\right|_{y_{\mathrm{O}_{2}, \text { turbine }} \mathrm{O}_{2}, y_{\mathrm{N}_{2}, \text { turbine }} \mathrm{N}_{2} \text { at } T_{\text {turbine }} \rightarrow T_{\text {exhaust }}}
$$

$\mathrm{CoO} / \mathrm{Co}_{3} \mathrm{O}_{4}$ particles are taken from the cold storage bin and fed directly to the solar thermochemical reactor. The solar thermochemical reactor was modeled as directly irradiated, requiring a quartz window that reflects a small portion of incoming solar irradiation to the environment, schematically shown in Figure 3. However, the spectral characteristics of the quartz window help to mitigate re-radiative losses as the window temperature is lower than the cavity temperature. A radiative exchange model was employed to determine the absorption efficiency of a solar thermochemical reactor composed of two surfaces: a quartz window (Surface 1) and a reactor cavity (Surface 2). The reactor cavity temperature was fixed to a specified temperature corresponding to typical CSP operation with a concentration ratio of $C=1000$ suns and direct normal irradiance of $I=1 \mathrm{~kW} / \mathrm{m}^{2}$. The relevant parameter is the area ratio between the two surfaces, therefore, a detailed cavity geometry is not specified. A semigray, two-band approximation was used to account for spectral dependency of the quartz glass: Semi-transparent and opaque wavelength intervals over the ranges of (1) $0-\lambda_{\mathrm{c}}$ and (2) $\lambda_{\mathrm{c}^{-}} \infty$, respectively, where $\lambda_{c}=4 \mu \mathrm{m}$ (Z'Graggen and Steinfeld 2004). Both surfaces were considered as 
diffuse and isothermal. The radiative exchange equation over the semi-transparent band (i.e., radiative band 1) for $N$ surfaces is given as (Loutzenhiser et al. 2010):

$$
\frac{q_{\mathrm{i}}^{(1)}}{1-\rho_{\mathrm{i}}}-\sum_{\mathrm{j}=1}^{\mathrm{N}}\left(\frac{\rho_{\mathrm{j}}}{1-\rho_{\mathrm{j}}}\right) F_{\mathrm{i}-\mathrm{j}} q_{\mathrm{j}}^{(1)}+H_{0, \mathrm{i}}^{(1)}=\frac{\alpha_{\mathrm{i}}}{1-\rho_{\mathrm{i}}} \sigma T_{\mathrm{i}}^{4} f\left(T_{\mathrm{i}} \lambda_{\mathrm{c}}\right)-\sum_{\mathrm{j}=1}^{\mathrm{N}}\left(\frac{\alpha_{\mathrm{j}}}{1-\rho_{\mathrm{j}}}\right) F_{\mathrm{i}-\mathrm{j}} \sigma T_{\mathrm{j}}^{4} f\left(T_{\mathrm{i}} \lambda_{\mathrm{c}}\right)
$$

where $q$ is the net radiative heat flux, $\rho$ is the slab reflectance, $F$ is the view factor, $\alpha$ is the slab absorptance, $H_{0}$ is the external irradiation to a surface, $\sigma$ is the Stefan-Boltzmann constant, $T$ is the surface temperature, $f$ is the radiative fractional function, and $i$ and $j$ are summing indices representing the emitting surface and incident surface(s) respectively. The incoming concentrated irradiation, assumed to be uniformly distributed and incident only on the cavity in the semi-transparent band, was represented as:

$$
H_{0,2}^{(1)}=\frac{\tau_{1} I C}{A_{\mathrm{r}}}
$$

where $\tau_{1}$ is the slab transmittance for the quartz glass, $I$ is the direct-normal solar irradiance, $C$ is the solar concentration ratio, and $A_{\mathrm{r}}$ is the ratio of the areas of the cavity to the quartz window. The radiative exchange equation over the opaque bandwidth (i.e., radiative band 2) for $N$ surfaces is given as:

$$
\frac{q_{\mathrm{i}}^{(2)}}{\varepsilon_{\mathrm{i}}}-\sum_{\mathrm{j}=1}^{\mathrm{N}}\left(\frac{1}{\varepsilon_{\mathrm{j}}}-1\right) F_{\mathrm{i}-\mathrm{j}} q_{\mathrm{j}}^{(2)}=\left(1-f\left(T_{\mathrm{i}} \lambda_{\mathrm{c}}\right)\right) \sigma T_{\mathrm{i}}^{4}-\sum_{\mathrm{j}=1}^{\mathrm{N}} F_{\mathrm{i}-\mathrm{j}}\left(1-f\left(T_{\mathrm{j}} \lambda_{\mathrm{c}}\right)\right) \sigma T_{\mathrm{i}}^{4}
$$

where $\varepsilon$ is the surface emittance. The net radiative flux between the reactor cavity and the quartz window in both radiative bands was solved using equations 8-10 along with an energy balance considering external convection, transmitted radiative energy through the quartz window, and radiative exchange to and from the surroundings, given as:

$$
\begin{aligned}
& q_{1}^{(1)}+q_{1}^{(2)}=\tau_{1}\left(\frac{q_{1}^{(1)}-\alpha_{1} f\left(T_{1} \lambda_{\mathrm{c}}\right) \sigma T_{1}^{4}}{1-\rho_{1}}\right)-h_{1}\left(T_{1}-T_{0}\right)-\alpha_{1} f\left(T_{1} \lambda_{\mathrm{c}}\right) \sigma T_{1}^{4} \\
& -\varepsilon_{1}\left[1-f\left(T_{1} \lambda_{\mathrm{c}}\right)\right] \sigma T_{1}^{4}+\sigma T_{0}^{4}
\end{aligned}
$$

where $h_{l}$ is the external convective heat transfer coefficient determined from free convection of a vertical surface (Maag et al. 2010), $\alpha_{1}$ is the absorptance, $\tau_{1}$ is the transmittance, $\rho_{1}$ is the 
reflectiance, $\varepsilon_{1}$ is the emittance of the quartz window, and $T_{1}$ refers to the window temperature.. The system of non-linear equations was solved iteratively until the window temperature converged to $<0.1 \mathrm{~K}$. The results were used to determine reactor absorption efficiencies for a range of reactor cavity temperatures and surface emittances, given as:

$$
\eta_{\mathrm{abs}}=\frac{\left[q_{2}^{(1)}+q_{2}^{(2)}\right] A_{\mathrm{r}}}{I C}
$$

$q_{2}^{(1)}+q_{2}^{(2)}$ was assumed solely to heat incoming particles and drive the chemical reaction. The reaction absorption efficiency was compared to the theoretical absorption efficiency assuming a perfectly insulated, blackbody, cavity-receiver with no convective/conductive heat losses to the environment, given as:

$$
\eta_{\text {abs,ideal }}=1-\frac{\sigma T_{\text {reactor }}^{4}}{I C}
$$

The incoming particles to the solar thermochemical reactor were assumed to enter the reactor without a carrier gas and completely reduce to $\mathrm{CoO}$ in a non-equilibrium reaction with $\mathrm{O}_{2}$ being continually removed. Spontaneous reaction occurs at $T_{\text {reactor }} \geq 1036.6 \mathrm{~K}$ at $p_{\mathrm{O} 2}=0.001$ bar where $\Delta \mathrm{G} \leq 0$ for $\mathrm{Co}_{3} \mathrm{O}_{4} \rightarrow 3 \mathrm{CoO}+1 / 2 \mathrm{O}_{2}$. Therefore, $T_{\text {reactor }}>1036.6 \mathrm{~K}$ were considered to assess the impact of additional sensible heat storage coupled to higher re-radiative heat losses. $T_{\text {reactor }}=$ $1050 \mathrm{~K}$ was chosen as it is just above the temperature where the $\mathrm{Co}_{3} \mathrm{O}_{4}$ thermolysis is spontaneous at 0.001 bar, ensuring conversion from $\mathrm{Co}_{3} \mathrm{O}_{4}$ to $\mathrm{CoO}$ and $\mathrm{O}_{2}$. The process heat required for complete reduction in the solar thermochemical reactor, the required concentrated solar irradiation (utilizing $\eta_{\text {abs }}$ calculated from the radiation exchange model), and heat rejected to the surroundings are given, respectively, as:

$$
\begin{gathered}
\dot{Q}_{\text {reactor }}=\left.\dot{n}_{\mathrm{CO}_{3} \mathrm{O}_{4} \text {,recovered }} \Delta H\right|_{\mathrm{Co}_{3} \mathrm{O}_{4} \text { at } T_{\text {recovered }} \rightarrow 3 \mathrm{CoO}+\frac{1}{2} \mathrm{O}_{2} \text { at } T_{\text {reactor }}}+\left.\dot{n}_{\mathrm{CoO}, \text { recovered }} \Delta H\right|_{\mathrm{CoO} \text { at } T_{\text {recovered }} \rightarrow T_{\text {reactor }}} \\
\dot{Q}_{\text {solar }}=\frac{\dot{Q}_{\text {reactor }}}{\eta_{\text {abs }}} \\
\dot{Q}_{\text {loss }}=\left(1-\eta_{\text {abs }}\right) \dot{Q}_{\text {solar }}
\end{gathered}
$$


The rate of exergy destruction in the solar thermochemical reactor to the surroundings is given as:

$$
\begin{aligned}
& \dot{\Xi}_{\mathrm{D}, \text { reactor }}=\left(1-\frac{T_{0}}{T_{\text {reactor }}}\right) \dot{Q}_{\text {solar }}-\left(1-\frac{T_{0}}{T_{0}}\right) \dot{Q}_{\text {loss }}+\left.\dot{n}_{\mathrm{Co}_{3} \mathrm{O}_{4}, \text { recovered }} \Delta \Xi_{\mathrm{f}}\right|_{\mathrm{Co}_{3} \mathrm{O}_{4} \text { at } T_{\text {recovered }} \rightarrow 3 \mathrm{CoO}+\frac{1}{2} \mathrm{O}_{2} \text { at } T_{\text {reactor }}, p_{\text {reactor }}} \\
& +\left.\dot{n}_{\mathrm{CoO} \text {,recovered }} \Delta \Xi_{\mathrm{f}}\right|_{\mathrm{CoO} \text { at } T_{\text {recovered }} \rightarrow T_{\text {reactor }}}
\end{aligned}
$$

Exergy destruction due to the solar input was calculated using $T_{\text {reactor }}$ according to previous literature (Steinfeld 2002, Loutzenhiser and Steinfeld 2011). An ideal cooling process to $T_{0}$ was assumed for the $\mathrm{O}_{2}$ stream exiting the solar thermochemical reactor. The heat rejected to the surroundings during the cooling process and the associated exergy destruction rate are given, respectively, as:

$$
\begin{gathered}
\dot{Q}_{\text {cool }}=\left.\dot{n}_{\mathrm{O}_{2}, \text { vac }} \Delta H\right|_{\frac{1}{2} \mathrm{O}_{2} \text { at } T_{\text {reactor }} \rightarrow T_{0}} \\
\dot{\Xi}_{\mathrm{D}, \text { cool }}=\left(1-\frac{T_{0}}{T_{\mathrm{b}, \mathrm{cool}}}\right) \dot{Q}_{\text {cool }}
\end{gathered}
$$

where $T_{\mathrm{b}, \text { cool }}$ is the effective temperature at the boundary of the cooling process, given as:

$$
T_{\mathrm{b}, \mathrm{cool}}=\frac{\dot{Q}_{\text {cool }}}{\left.\dot{n}_{\mathrm{O}_{2}, \mathrm{vac}} \Delta S\right|_{\frac{1}{2} \mathrm{O}_{2} \text { at } T_{\text {reactor }} \rightarrow T_{0}}}
$$

A reversible vacuum pump was assumed to operate isothermally at $T_{0}$ to reduce the pressure in the solar thermochemical reactor. The rates of work and heat transfer to the environment are given, respectively, as:

$$
\begin{gathered}
\dot{W}_{\text {vac }}=-\left.\dot{n}_{\mathrm{O}_{2}, \text { vac }} T_{0} \Delta S\right|_{\mathrm{O}_{2} \text { at } T_{0}, p_{\text {reactor }} \rightarrow p_{0}} \\
\dot{Q}_{\text {vac }}=\dot{W}_{\text {vac }}
\end{gathered}
$$

To assess the potential of the CSP facility, the overall cycle efficiency is given as:

$$
\eta_{\text {cycle }}=\frac{\dot{W}_{\text {turbine }}-\dot{W}_{\text {comp }}-\dot{W}_{\text {vac }}}{\dot{Q}_{\text {solar }}}
$$




\section{Results and discussion}

Parameters for the thermodynamic and exergy analyses are provided in Table 1.

$T_{\text {recover }}$ and $T_{\text {turbine }}$ as functions of $\dot{n}_{\text {air }}$ were determined using the energy balance across the reoxidizer employing the thermodynamic constraints previously described and are given in Figure 4 at $T_{\text {reactor }}=1050 \mathrm{~K}$ and $p_{\text {comp }}=30$ bar. At $\dot{n}_{\text {air }}<13.7 \mathrm{~mol} / \mathrm{s}, T_{\text {turbine }} \sim T_{\text {turbine,max }}$ and is greater than $T_{\text {reactor }}$ as calculated from the thermodynamic limit where $\Delta G=0 . T_{\text {turbine }}$ increases slightly with $\dot{n}_{\text {air }}$ as $\mathrm{O}_{2}$ concentration increases at the airflow exit, favoring higher equilibrium temperatures and reaches a maximum of $1344.7 \mathrm{~K}$ at $\dot{n}_{\text {air }}=13.7 \mathrm{~mol} / \mathrm{s} . T_{\text {recover }}$ decreases rapidly with $\dot{n}_{\text {air }}$, as more heat exits at the turbine to maintain $T_{\text {turbine }}=T_{\text {turbine,max. }} T_{\text {recover }}$ achieves a minimum possible temperature at $\dot{n}_{\text {air }}=13.7 \mathrm{~mol} / \mathrm{s}$ where $T_{\text {recover }}=T_{\text {comp }}$, corresponding to rapid decreases in $T_{\text {turbine }}$ for increasing $\dot{n}_{\text {air }}>13.7 \mathrm{~mol} / \mathrm{s}$ as greater airflows absorb greater sensible heat.

$\dot{\Xi}_{\text {D,re-oxidizer }}$ and $X$ are given as functions of $\dot{n}_{\text {air }}$ in Figure 5 at $T_{\text {reactor }}=1050 \mathrm{~K}$ and $p_{\text {comp }}=30$ bar.

The $\dot{\Xi}_{\text {D,re-oxidizer }}$ initially increases until it reaches a maximum of $11.8 \mathrm{~kW}$ at $\dot{n}_{\text {air }}=9.8 \mathrm{~mol} / \mathrm{s}$, which corresponds the largest $\Delta \Xi_{f}$ between the particle and air streams. $X$ increases as lower particle recovery temperatures favor complete conversion from $\mathrm{CoO}$ to $\mathrm{Co}_{3} \mathrm{O}_{4}$. Once $T_{\text {recover }}=T_{\text {comp }}, X$ remains constant at 0.985 , which corresponds to a minimum $\dot{\Xi}_{\mathrm{D}, \text { e-oxidizer }}$ at $\dot{n}_{\text {air }}=$ $13.7 \mathrm{~mol} / \mathrm{s}$ and the smallest $\Delta \Xi_{f}$ between the particle and air streams. The $\dot{\Xi}_{\mathrm{D}, \mathrm{re}-\mathrm{oxidizer}}$ then begins a monotonic increase with larger $\dot{n}_{\text {air }}$ due to the introduction of additional irreversibilities related to a decreasing $T_{\text {turbine. }}$.

A comparison of $\eta_{\text {abs }}$ as a function of $A_{\mathrm{r}}$ is given in Figure 6. The $\eta_{\text {abs }}$ as a function of $A_{\mathrm{r}}$ is given in Figure $6 \mathrm{a}$ at $T_{\text {reactor }}=1050 \mathrm{~K}$ for a range of $\varepsilon_{2}$. The $\eta_{\mathrm{abs}}$ rapidly increases with an increasing $A_{\mathrm{r}}$ $\leq 3$ for $\varepsilon_{2} \leq 0.8$, after which the curves begin to asymptotically approach $\eta_{\text {abs }}$ for $\varepsilon_{2}=1$ (i.e., a blackbody cavity). At higher $A_{\mathrm{r}}$, a large portion of the incoming solar irradiation is absorbed due to an increase in internal reflections and subsequent absorptions, resulting in near blackbody behavior. Blackbody behavior is also more closely approximated as $\varepsilon_{2}$ approaches 1 for all $A_{\mathrm{r}}$. 
The maximum $\eta_{\text {abs }}$ never reaches the $\eta_{\text {abs,ideal }}$ as the quartz window reflects a portion of incoming solar radiation, subsequently reducing $H_{0,2}$ incident upon the cavity walls. The $\eta_{\mathrm{abs}}$ as a function of $A_{\mathrm{r}}$ for a range of $T_{\text {reactor }}$ at $\varepsilon_{2}=0.8$ is provided in Figure $6 \mathrm{~b}$. The $\eta_{\mathrm{abs}}$ at all $T_{\text {reactor }}$ increases initially and then begins to asymptotically approach the limit for a blackbody cavity. As $T_{\text {reactor }}$ increases, $\eta_{\text {abs }}$ decreases as result of increased internal cavity re-radiation, increasing both emissions and convective losses due to a higher $T_{1}$ which increases from $820 \mathrm{~K}$ to $1010 \mathrm{~K}$. Active cooling is often required for solar thermochemical reactors to ensure window durability (Muller et al. 2005, Schunk et al. 2008, Villasmil et al. 2014), adding a small parasitic load not included in this analysis. A higher $T_{\text {reactor }}$ results in a more efficient power cycle by increasing the Carnot efficiency of the cycle, but the efficiency is offset by increased re-radiative losses to the environment. A $T_{\text {reactor }}=1106 \mathrm{~K}$ is the optimal operating temperature for $C=1000$ suns and $I=1$ $\mathrm{kW} / \mathrm{m}^{2}$ (Steinfeld and Palumbo 2001), assuming an ideal blackbody solar receiver with an ideal heat engine (i.e., Carnot cycle) operating between hot and cold reservoirs with temperatures equal to $T_{\text {reactor }}$ and $T_{0}$, respectively.

$\dot{Q}_{\text {solar }}, \dot{Q}_{\text {loss }}$, and $\dot{Q}_{\text {cool }}$ as functions of $\dot{n}_{\text {air }}$ are given in Figure 7 at $T_{\text {reactor }}=1050 \mathrm{~K}$ and $p_{\text {comp }}=30$ bar. $\dot{Q}_{\text {solar }}$ rapidly increases with $\dot{n}_{\text {air }}$ as additional process heat is required to both sensibly heat and fully reduce incoming $\mathrm{CoO} / \mathrm{Co}_{3} \mathrm{O}_{4}$ particles. The recovered particles decrease in temperature and increase in concentration of $\mathrm{Co}_{3} \mathrm{O}_{4}$ with increasing $\dot{n}_{\text {air }}$, as more heat is transferred to the air stream. When $\dot{n}_{\text {air }}<13.7 \mathrm{~mol} / \mathrm{s}, \dot{Q}_{\text {solar }}$ and $\dot{Q}_{\text {loss }}$ increase with $\dot{n}_{\text {air }}$ as $T_{\text {recover }}$ decreases and $X$ increases, requiring more heat to drive the $\mathrm{Co}_{3} \mathrm{O}_{4}$ thermolysis. $\dot{Q}_{\text {quench }}$ increases with $\dot{n}_{\text {air }}$ as higher $X$ results in more $\mathrm{O}_{2}$ evolution in the solar thermochemical reactor. Maximum values of $\dot{Q}_{\text {solar }}=306 \mathrm{~kW}$ and $\dot{Q}_{\text {loss }}=48 \mathrm{~kW}$ correspond to $\dot{n}_{\text {air }}=13.7 \mathrm{~mol} / \mathrm{s}$, after which $T_{\text {recover }}=T_{\text {comp }}$ and $X$ remain constant, resulting in constant $\dot{Q}_{\text {solar }}$ and $\dot{Q}_{\text {loss }}$ (i.e., the solar thermochemical reactor requires no additional heat). At $\dot{n}_{\text {air }}>13.7 \mathrm{~mol} / \mathrm{s}$, the equilibrium compositions of the incoming particles remain constant, resulting in a constant $\dot{Q}_{\text {cool }}$ as no additional $\mathrm{O}_{2}$ is extracted by the vacuum pump from the solar thermochemical reactor. 
$\dot{W}_{\text {turbine }}, \dot{W}_{\text {comp }}$, and $\dot{W}_{\text {vac }}$ are given as functions of $\dot{n}_{\text {air }}$ in Figure 8 at $T_{\text {reactor }}=1050 \mathrm{~K}$ and $p_{\text {comp }}=$ 30 bar. $\dot{W}_{\text {turbine }}$ monotonically increases with $\dot{n}_{\text {air }}$ until reaching $\dot{n}_{\text {air }}=13.7 \mathrm{~mol} / \mathrm{s}$. At $\dot{n}_{\text {air }}=13.7$ $\mathrm{mol} / \mathrm{s}$, increases in airflow entering the turbine are offset by lower $T_{\text {turbine, }}$ resulting in a continued, shallower increase in $\dot{W}_{\text {turbine }} \cdot \dot{W}_{\text {comp }}$ increases steadily as $\dot{n}_{\text {air }}$ increases constantly and the temperature difference across the turbine remains the same. $\dot{W}_{\text {vac }}$ increases as a result of greater $\mathrm{O}_{2}$ production in the reactor until $\dot{n}_{\mathrm{air}}=13.7 \mathrm{~mol} / \mathrm{s}$ and $\dot{W}_{\mathrm{vac}}=8.5 \mathrm{~kW}$ at which the composition of the entering particle stream and the $\mathrm{O}_{2}$ produced are constant. The $\dot{W}_{\text {vac }}$ is a minor parasitic load compared to $\dot{W}_{\text {comp }}$ and $\dot{W}_{\text {turbine }}$.

$\dot{\Xi}_{\mathrm{D}, \text { reactor }}$ and $\dot{\Xi}_{\mathrm{D}, \text { cool }}$ are compared to $X$ as functions of $\dot{n}_{\text {air }}$ and given in Figure 9 at $T_{\text {reactor }}=1050 \mathrm{~K}$ and $p_{\text {comp }}=30$ bar. The increase in $X$ with $\dot{n}_{\text {air }}$ requires additional $\dot{Q}_{\text {solar }}$ to sensibly heat and fully-reduce the $\mathrm{CoO} / \mathrm{Co}_{3} \mathrm{O}_{4}$ particle stream and overcome heat losses. Additional $\dot{Q}_{\text {solar }}$ greatly increases the incoming thermal exergy related to heat transfer across a boundary. However, once $\dot{Q}_{\text {solar }}$ and $T_{\text {recover }}$ are constant for $\dot{n}_{\text {air }} \geq 13.7 \mathrm{~mol} / \mathrm{s}$, both entering and exiting exergy flows become fixed and $\dot{\Xi}_{\mathrm{D}, \text { cool }}=37.5 \mathrm{~kW}$. Small $\dot{\Xi}_{\mathrm{D}, \text { cool }}$ increases are correlated to increasing $\mathrm{O}_{2}$ flowrates exiting the solar thermochemical reactor and the $\dot{\Xi}_{\mathrm{D}, \text { cool }}$ plateaus at a maximum at $6.2 \mathrm{~kW}$ once $X$ is constant.

Comparisons of $\eta_{\text {cycle }}$ as a function of $\dot{n}_{\text {air }}$ are given in Figure 10 for a range of $T_{\text {reactor }}$ and $p_{\text {comp. }}$ For all of the analyses, $\eta_{\text {cycle }}$ increases with larger $\dot{n}_{\text {air }}$ for different $T_{\text {reactor }}$ and $p_{\text {comp }} \cdot \eta_{\text {cycle }}$ as a function of $\dot{n}_{\text {air }}$ is given in Figure $10 \mathrm{a}$ at $T_{\text {reactor }}=1050 \mathrm{~K}$ for a range of $p_{\text {comp }}$ between 5-30 bar, a pressure range suitable for gas turbines. Increasing to $p_{\text {comp }}=30$ bar results in $\eta_{\text {cycle }}$ nearing $44 \%$ compared with $\eta_{\text {cycle }}$ of $26 \%$ for a $p_{\text {comp }}=5$ bar. The increased $\eta_{\text {cycle }}$ is a result of higher $T_{\text {turbine }}$ (Figure 1) and lower $T_{\text {exhaust }}$, directly translating to more $\dot{W}_{\text {turbine }}$. Increases in $\dot{W}_{\text {turbine }}$ more than offset the additional $\dot{W}_{\text {comp }}$ required. Operation at lower $\dot{n}_{\text {air }}$ resulted in some unreacted CoO, reducing $\dot{Q}_{\text {solar }}$ while decreasing the energy density of the redox material. In addition, $\mathrm{T}_{\text {recover,min }}$ 
increases at higher $\mathrm{p}_{\text {comp }}$, decreasing the required amount of $\dot{Q}_{\text {solar }}$. Increasing $T_{\text {reactor }}$ results in decreases in $\eta_{\text {cycle }}$ as $T_{\text {turbine }}$ is thermodynamically limited by $3 \mathrm{CoO}+1 / 2 \mathrm{O}_{2}$ reaction. and remains relatively constant as shown in Figure $10 \mathrm{~b}$. Increases in $T_{\text {reactor }}$ at $p_{\text {comp }}=30$ bar result in larger $\dot{Q}_{\text {solar }}$ due to larger $\dot{Q}_{\text {loss }}$ that do not correspond to increases in $\dot{W}_{\text {turbine }}$. An additional analysis was performed assuming no reactions (i.e., SES) with $1 \mathrm{~mol} / \mathrm{s} \mathrm{of} \mathrm{Co}_{3} \mathrm{O}_{4}$ flowing through the system. $\eta_{\text {cycle }}$ was $51 \%$ for operation at $T_{\text {reactor }}=1050 \mathrm{~K}, p_{\text {comp }}=30 \mathrm{bar}$, and $\dot{n}_{\text {air }}=16 \mathrm{~mol} / \mathrm{s} \mathrm{compared} \mathrm{to}$ $\eta_{\text {cycle }}=44 \%$ under the same conditions with reactions. However, the improved efficiency of SES comes at the expense of lower energy densities, requiring more materials handling and larger infrastructure (e.g., storage bins, etc.) throughout the system to achieve the same amount of $\dot{W}_{\text {turbine }}$.

\section{Verification}

Thermodynamic analysis can be verified by performing an energy balance with a defined control volume that encompasses all components. This was done to compute the incoming concentrated solar irradiation, given as:

$$
\begin{aligned}
& \dot{Q}_{\text {solar,ver }}=\dot{Q}_{\text {loss }}+\dot{Q}_{\text {cool }}+\dot{Q}_{\text {pump }}+\dot{W}_{\text {turbine }}-\dot{W}_{\text {vac }}-\dot{W}_{\text {comp }}
\end{aligned}
$$

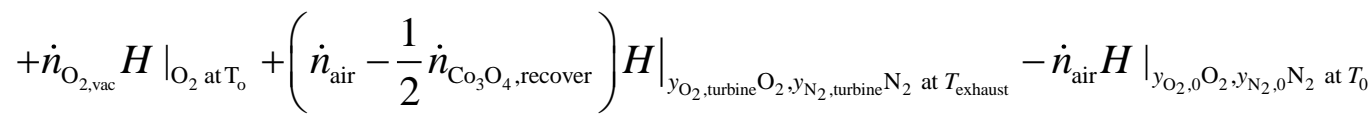

For operation at $T_{\text {reactor }}=1050 \mathrm{~K}, p_{\text {comp }}=30 \mathrm{bar}$, and $\dot{n}_{\text {air }}=16 \mathrm{~mol} / \mathrm{s}$ both $\dot{Q}_{\text {solar }}$ and $\dot{Q}_{\text {solar, ver }}$ are equal to $306 \mathrm{~kW}$.

The available work, the sum of all of the work flows, exergy destructions, and the exergy flow at the exit of the turbine, can be used to determine the maximum cycle efficiency. This efficiency is comparable to a Carnot cycle operating between hot and cold temperature reservoirs of $T_{\mathrm{H}}=$ $T_{\text {reactor }}$ and $T_{\mathrm{C}}=T_{0}$, respectively. The maximum efficiency is given as:

$$
\begin{aligned}
& \eta_{\text {max }}=\frac{\dot{W}_{\text {turbine }}-\dot{W}_{\text {comp }}-\dot{W}_{\text {vac }}+\dot{\Xi}_{\mathrm{d}, \text { reoxidizer }}+\dot{\Xi}_{\mathrm{d}, \text { reactor }}+\left(\dot{n}_{\text {air }}-\frac{1}{2} \dot{n}_{\mathrm{C}_{3} \mathrm{O}_{4}, \text { recover }}\right)}{\dot{Q}_{\text {solar }}} \Xi_{\mathrm{f}_{\mathrm{O}_{2}, \text { turtine }} \mathrm{O}_{2}, y_{\mathrm{N}_{2}, \text { turbine }} \mathrm{N}_{2} \text { at } p_{0}, T_{\text {exhaust }}} \\
& =1-\frac{T_{0}}{T_{\text {reactor }}}=\eta_{\text {Carnot }}
\end{aligned}
$$


For operation at $T_{\text {reactor }}=1050 \mathrm{~K}, p_{\text {comp }}=30 \mathrm{bar}$, and $\dot{n}_{\text {air }}=16 \mathrm{~mol} / \mathrm{s}$ both $\eta_{\max }$ and $\eta_{\text {Carnot }}$ are equal to 0.716 .

A control volume excluding the solar thermochemical reactor, storage bins, and vacuum pump was used to compute the Air Brayton cycle efficiency, represented as:

$$
\eta_{\text {Brayton }}=\frac{\dot{W}_{\text {turbine }}-\dot{W}_{\text {comp }}}{\left.\dot{n}_{\text {air }} \Delta H\right|_{y_{\mathrm{O}_{2}} \mathrm{O}_{2}, y_{\mathrm{N}_{2}} \mathrm{~N}_{2} \text { at } T_{\text {comp }} \rightarrow T_{\text {turbine }}}}
$$

Some $\mathrm{O}_{2}$ was consumed during re-oxidation between the compressor and turbine. This was compared to the cycle efficiency of an ideal Air-Standard Brayton cycle, represented as:

$$
\eta_{\text {Brayton,ideal }}=1-\frac{1}{\left(p_{\text {comp }} / p_{0}\right)^{(k-1) / k}}
$$

where $k$ is the specific heat ratio for air. For operation at $T_{\text {reactor }}=1050 \mathrm{~K}, p_{\text {comp }}=30$ bar, $\dot{n}_{\text {air }}=$ $16 \mathrm{~mol} / \mathrm{s}, \eta_{\text {Brayton }}$ is $55 \%$ while $\eta_{\text {Brayton,ideal }}$ is $62 \%$. Exergy destruction within the re-oxidizer due to the chemical reaction impacts the performance of the Air Brayton cycle.

\section{Summary and conclusions}

A thermodynamic analysis was performed for an Air- Brayton cycle coupled to a two-step thermochemical cycle for heat storage based on $\mathrm{Co}_{3} \mathrm{O}_{4} / \mathrm{CoO}$ redox reactions through direct integration of direct counter-flow heat exchange between the high-temperature particles and the working fluid. Cycle performance was quantified and major sources of irreversibilities (i.e., exergy destruction) were identified using exergy destruction results. The analysis used a windowed cavity receiver for a solar thermochemical reactor to directly heat $\mathrm{CoO} / \mathrm{Co}_{3} \mathrm{O}_{4}$ particles with concentrated solar irradiation. For a solar thermochemical reactor temperature of $1050 \mathrm{~K}$ and an outlet compressor pressure of $30 \mathrm{bar}$, the maximum cycle efficiency approached $44 \%$. The cycle efficiency decreased to $26 \%$ for outlet compressor pressures of 5 bar. Operation at higher solar thermochemical reactor temperatures resulted in decreased cycle efficiencies, while increased airflow rates across the compressor increased cycle efficiencies for the range of solar thermochemical reactor temperature and outlet compressor pressures considered. The 
dominant source of exergy destruction was in the solar thermochemical reactor, due to the incoming concentrated solar irradiation used to heat entering particles and thermolyze $\mathrm{Co}_{3} \mathrm{O}_{4}$ to $\mathrm{CoO}$ and $\mathrm{O}_{2}$. Smaller exergy destruction rates were determined for the re-oxidizer and the cooling process. The analysis shows the potential of directly integrating a two-step solar thermochemical cycle into an Air Brayton cycle as the cycle is capable of effectively utilizing the available exergy while incorporating heat storage, culminating in higher operating efficiencies.

\section{Acknowledgements}

This work has been financially supported by the U.S. Department of Energy, SunSHOT Initiative for the High Performance Reduction/Oxidation Metal Oxides for Thermochemical Energy Storage (PROMOTES) project: DE-FOA- 0000805-1541. Contributions by A. Muroyama were supported by the National Science Foundation Graduate Research Fellowship under Grant No. DGE-1148903. 


\section{Nomenclature}

$A_{\mathrm{r}}=$ area ratio between cavity and quartz window

$C=$ solar concentration ratio

$f=$ blackbody fraction

$F=$ geometric view factor

$G=$ Gibb's free energy function

$H=$ total enthalpy

$H_{0,2}=$ transmitted solar irradiance incident on cavity

$h_{1}=$ external convective heat transfer coefficient

$k=$ specific heat ratio for air

$N=$ number of surfaces in solar thermochemical reactor

$\dot{n}_{\text {air }}=$ molar flow rate of air

$\dot{n}_{\text {CoO,reactor }}=$ molar flow rate for $\mathrm{CoO}$ produced in solar thermochemical reactor

$\dot{n}_{\mathrm{CoO}, \text { recover }}=$ molar flow rate for $\mathrm{CoO}$ recovered from re-oxidizer

$\dot{n}_{\mathrm{Co}_{3} \mathrm{O}_{4} \text {, recover }}=$ molar flow rate for $\mathrm{Co}_{3} \mathrm{O}_{4}$ recovered from re-oxidizer

$\dot{n}_{\mathrm{O}_{2} \text {,vac }}=$ molar flow rate for evolved $\mathrm{O}_{2}$ stream in solar thermochemical reactor

$p_{0}=$ ambient air pressure

$p_{\text {comp }}=$ compressed air pressure

$p_{\text {reactor }}=$ solar thermochemical reactor pressure

$q=$ net radiative flux at surface

$q_{\text {loss }}=$ net radiative flux lost to atmosphere

$q_{\text {solar }}=$ net radiative flux from concentrated solar

$q_{1}=$ net radiative flux at the inner window surface

$q_{2}=$ net radiative flux at the reactor cavity surface

$\dot{Q}_{\text {loss }}=$ external heat flow from re-radiative, emissive, transmissive, and convective losses from the window

$\dot{Q}_{\text {cool }}=$ heat flow output from cooled $\mathrm{O}_{2}$

$\dot{Q}_{\text {reactor }}=$ heat flow input required for sensible heating and complete thermolysis of particle flow

$\dot{Q}_{\text {solar }}=$ concentrated solar heat input 
$S=$ total entropy

$T_{0}=$ ambient temperature

$T_{\mathrm{b}, \text { cool }}=$ effective temperature for cooled $\mathrm{O}_{2}$

$T_{\text {comp }}=$ compressor outlet airflow temperature

$T_{\text {exhaust }}=$ temperature of depleted $-\mathrm{O}_{2}$ airflow from turbine outlet

$T_{\text {reactor }}=$ solar thermochemical reactor temperature

$T_{\text {recover }}=$ temperature of particle flow recovered from re-oxidizer

$T_{\text {recover,min }}=$ minimum possible temperature of particle flow recovered from re-oxidizer

$T_{\text {solar }}=$ assumed blackbody temperature of sun

$T_{\text {turbine }}=$ temperature of depleted $-\mathrm{O}_{2}$ airflow from turbine inlet

$T_{\text {turbine,max }}=$ maximum possible temperature of depleted $-\mathrm{O}_{2}$ airflow from turbine inlet

$T_{1}=$ quartz window temperature

$\dot{W}_{\text {vac }}=$ work input rate for evacuating $\mathrm{O}_{2}$

$\dot{W}_{\text {comp }}=$ work input rate for compressing airflow

$\dot{W}_{\text {turbine }}=$ work output rate from turbine

$X=$ conversion extent

$y_{\mathrm{O}_{2}, 0}=$ atmospheric mole fraction of $\mathrm{O}_{2}$

$y_{\mathrm{O}_{2}, \text { turbine }}=$ mole fraction of $\mathrm{O}_{2}$ in turbine

$y_{\mathrm{N}_{2}, 0}=$ atmospheric mole fraction of $\mathrm{N}_{2}$

$y_{\mathrm{N}_{2}, \text { turbine }}=$ mole fraction of $\mathrm{N}_{2}$ in turbine

\section{Greek letters}

$\alpha_{2}=$ cavity absorptance

$\alpha_{1}=$ surface absorptance at window

$\varepsilon_{1}=$ surface emittance at window

$\varepsilon_{2}=$ cavity emittance

$\eta_{\mathrm{abs}}=$ solar thermochemical reactor absorption efficiency

$\eta_{\text {abs,ideal }}=$ ideal solar thermochemical reactor absorption efficiency

$\eta_{\text {Brayton }}=$ Air Brayton cycle efficiency 


$$
\begin{aligned}
& \eta_{\text {Brayton,ideal }}=\text { ideal Air-Standard Brayton cycle efficiency } \\
& \eta_{\text {Carnot }}=\text { CSP facility Carnot efficiency } \\
& \eta_{\text {cycle }}=\text { CSP facility efficiency } \\
& \eta_{\text {max }}=\text { maximum possible CSP facility efficiency } \\
& \lambda_{c}=\text { transparent to opaque transition wavelength for quartz window } \\
& \rho_{2}=\text { surface reflectance at window } \\
& \rho_{1}=\text { surface reflectance at window } \\
& \sigma=\text { Stefan-Boltzmann constant } \\
& \tau_{1}=\text { surface transmittance at window } \\
& \dot{\Xi}_{\mathrm{D}, \text { reactor }}=\text { exergy destruction rate for solar thermochemical reactor } \\
& \dot{\Xi}_{\mathrm{D}, \mathrm{re}-\mathrm{oxidizer}}=\text { exergy destruction rate for re-oxidizer } \\
& \dot{\Xi}_{\mathrm{D}, \text { quench }}=\text { exergy destruction rate for cooling } \mathrm{O}_{2} \\
& \Xi_{\mathrm{f}}=\text { total exergy flow }
\end{aligned}
$$




\section{References}

Abanades, S., Charvin, P., Flamant, G. and Neveu, P., 2006. Screening of water-splitting thermochemical cycles potentially attractive for hydrogen production by concentrated solar energy. Energy. 31, 28052822.

Agrafiotis, C., Roeb, M., Schmücker, M. and Sattler, C., 2014. Exploitation of thermochemical cycles based on solid oxide redox systems for thermochemical storage of solar heat. Part 1: Testing of cobaltoxide powders. Sol. Energy. 102, 189-211.

Bayón, R., Rojas, E., Valenzuela, L., Zarza, E. and León, J., 2010. Analysis of the experimental behaviour of a $100 \mathrm{kWth}$ latent heat storage system for direct steam generation in solar thermal power plants. Appl. Therm. Eng. 30, 2643-2651.

Bilgen, E., Ducarroir, M., Foex, M., Sibieude, F. and Trombe, F., 1977. Use of solar energy for direct and two-step water decomposition cycles. Int. J. Hydrogen Energy. 2, 251-257.

Ermanoski, I., Siegel, N. P. and Stechel, E. B., 2013. A New Reactor Concept for Efficient SolarThermochemical Fuel Production. J. Sol. Energy Eng. 135.

Fletcher, E. A., 2000. Solarthermal Processing: A Review. J. Sol. Energy Eng. 123, 63-74.

Hischier, I., Leumann, P. and Steinfeld, A., 2012. Experimental and numerical analyses of a pressurized air receiver for solar-driven gas turbines. Sol. Energy. 134.

Ho, C., Christian, J., Gill, D., Moya, A., Jeter, S., Abdel-Khalik, S., Sadowski, D., Siegel, N., Al-Ansary, H., Amsbeck, L., Gobereit, B. and Buck, R., 2014. Technology advancements for next generation falling particle receivers. Energy Procedia. 49, 398-407.

Kodama, T., 2003. High-temperature solar chemistry for converting solar heat to chemical fuels. Prog. Energy Combust. Sci. 29, 567-597.

Liu, M., Saman, W. and Bruno, F., 2012. Review on storage materials and thermal performance enhancement techniques for high temeprature phase change thermal storage systems. Renew. Sust. Energ. Rev. 16, 2118-2132.

Loutzenhiser, P. G., Meier, A. and Steinfeld, A., 2010. Review of the Two-Step H20/CO2-Splitting Solar Thermochemical Cycle Based on Zn/ZnO Redox Reactions. Materials. 3, 4922-4938.

Loutzenhiser, P. G. and Steinfeld, A., 2011. Solar syngas production from CO2 and H2O in a two-step thermochemical cycle via $\mathrm{Zn} / \mathrm{ZnO}$ redox reactions: Thermodynamic cycle analysis. Int. J. Hydrogen Energy. 36, 12141-12147.

Loutzenhiser, P. G., Tuerk, O. and Steinfeld, A., 2010. Production of Si by vacuum carbothermal reduction of $\mathrm{SiO} 2$ using concentrated solar energy. JOM. 62, 49-54.

Lovegrove, K., Luzzi, A. and Kreetz, H., 1999. A solar-driven ammonia-based thermochemical energy storage system. Sol. Energy. 67, 309-316.

Lovegrove, K., Luzzi, A., McCann, M. and Freitag, O., 1999. Exergy Analysis of Ammonia-Based Solar Thermochemical Power Systems. Sol. Energy. 66, 103-115.

Maag, G., Falter, C. and Steinfeld, A., 2010. Temperature of a Quartz/Sapphire Window in a Solar Cavity-Receiver. J. Sol. Energy Eng. 133, 014501-014501.

Mahfuz, M. H., Kamyar, A., Afshar, O., Sarraf, M., Anisur, M. R., Kibria, M. A., Saidur, R. and Metselaar, I. H. S. C., 2014. Exergetic analysis of a solar thermal power system with PCM storage. Energy Convers. Manage. 78, 486-492. 
Medrano, M., Gil, A., Martorell, I., Potau, X. and Cabeza, L., 2010. State of the art on high-temperature thermal energy storage for power generation. Part 2-Case studies. Renewable and Sustainable Energy Reviews. 14, 56-72.

Meier, A. and Sattler, C., 2009. Solar Fuels from Concentrated Sunlight. Solar Power and Chemical Energy Systems Implementing Agreement of the International Energy Agency. SolarPACES.

Moran, M. and Shapiro, H., 2000. Fundamentals of Engineering Thermodynamics. John Wiley and Sons, Inc., New York.

Muller, R., Haerberling, P. and Palumbo, R. D., 2005. Further advances toward the development of a direct heating solar thermal chemical reactor for the thermal dissociation of $\mathrm{ZnO}(\mathrm{s})$. Sol. Energy. 80, 500511.

Neises, M., Tescari, S., de Oliveira, L., Roeb, M., Sattler, C. and Wong, B., 2012. Solar-heated rotary kiln for thermochemical energy storage. Sol. Energy. 86, 3040-3048.

Pagkoura, C., Karagiannakis, G., Zygogianni, A., Lorentzou, S., Kostoglou, M., Konstandopoulos, A. G., Rattenburry, M. and Woodhead, J. W., 2014. Cobalt oxide based structured bodies as redox thermochemical heat storage medium for future CSP plants. Sol. Energy. 108, 146-163.

Perkins, C. and Weimer, A. W., 2009. Solar-thermal production of renewable hydrogen -- a review. AIChE J. 55, 286-293.

Pitz-Paal, R., Amin, A., Bettzüge, M., Eames, P., Fabrizi, F., Flamant, G., Garcia Novo, F., Holmes, J., Kribus, A., van der Laan, H., Lopez, C., Papagiannakopoulos, P., Pihl, E., Smith, P. and Wagner, H.-J., 2012. Concentrating solar power in Europe, the Middle East and North Africa: achieving its potential. EPJ Web of Conferences. 33, 03004.

Roine, A., 2002. HSC chemistry. Finland: Outokumpu Res Oy.

Schunk, L. O., Haeberling, P., Wepf, S., Wuillemin, D., Meier, A. and Steinfeld, A., 2008. A ReceiverReactor for the Solar Thermal Dissociation of Zinc Oxide. J. Sol. Energy Eng. 130, 021009-021009.

Sharma, A., Tyagi, V. V., Chen, C. R. and Buddhi, D., 2009. Review on storage materials and thermal performance enchancement techniques for high temperature phase change thermal storage systems. Renew. Sust. Energ. Rev. 13, 318-345.

Siegel, N. and Kolb, G., 2009. Design and on-sun testing of a solid particle receiver protype 2008 2nd International Conference on Energy Sustainability, ES 2008, August 10, 2008 - August 14, 2008, Jacksonville, FL, United states, ASME.

Steinfeld, A., 2002. Solar hydrogen production via a two-step water-splitting thermochemical cycle based on $\mathrm{Zn} / \mathrm{ZnO}$ redox reactions. Int. J. Hydrogen Energy. 27, 611-619.

Steinfeld, A., 2005. Solar thermochemical production of hydrogen -- a review. Sol. Energy. 78, 603-615.

Steinfeld, A. and Palumbo, R., 2001. Solar Thermochemical Process Technology. Encyclopedia of Physical Science and Technology. R. A. Meyers. Academic Press. 15, 237-256.

Steinmann, W. D., Laing, D. and Tamme, R., 2009. Development of PCM Storage for Process Heat and Power Generation. J. Sol. Energy Eng. 131, 041009-041009.

Sturzenegger, M. and Nüesch, P., 1999. Efficiency analysis for a manganese-oxide-based thermochemical cycle. Energy. 24, 959-970.

Villasmil, W., Brkic, M., Wuillemin, D., Meier, A. and Steinfeld, A., 2014. Pilot scale demonstration of a 100-kWth solar thermochemical plant for the thermal dissociation of ZnO. Journal of Solar Energy Engineering, Transactions of the ASME. 136. 
Wong, B., 2011. Thermochemical Heat Storage for Concentrated Solar Power, Final Report for the US Department of Energy. San Diego, CA, USA.

Xu, C., Wang, Z., Li, X. and Sun, F., 2011. Energy and exergy analysis of solar power tower plants. Appl. Therm. Eng. 31, 3904-3913.

Z'Graggen, A. and Steinfeld, A., 2004. Radiative Exchange Within a Two-Cavity Configuration With a Spectrally Selective Window. J. Sol. Energy Eng. 126, 819-822. 


\section{Tables}

Table 1. Properties and values for the thermodynamic analysis of the Air Brayton cycle integrated with thermochemical heat storage.

\begin{tabular}{cc}
\hline \hline Property & Value $(\mathrm{s})$ \\
\hline$I$ & $1 \mathrm{~kW} \cdot \mathrm{m}^{-2}$ \\
$T_{\text {solar }}$ & $1000 \mathrm{suns}$ \\
$T_{0}$ & $5780 \mathrm{~K}$ \\
$p_{0}$ & $298.15 \mathrm{~K}$ \\
$T_{\text {reactor }}$ & $1 \mathrm{bar}$ \\
$p_{\text {reactor }}$ & $1050-1250 \mathrm{~K}$ \\
$p_{\text {comp }}$ & $0.001 \mathrm{bar}$ \\
$A_{\mathrm{r}}$ & $5-30 \mathrm{bar}$ \\
$\dot{n}_{\text {CoO,reactor }}$ & 5 \\
$\dot{n}_{\text {air }}$ & $3 \mathrm{~mol} / \mathrm{s}$ \\
$\alpha_{1}$ & $8-16 \mathrm{~mol} / \mathrm{s}$ \\
$\rho_{1}$ & $0(0-4 \mu \mathrm{m})$ and $0.9(4 \mu \mathrm{m}-\infty)$ \\
$\tau_{1}$ & $0.06(0-4 \mu \mathrm{m})$ and $0.1(4 \mu \mathrm{m}-\infty)$ \\
$\varepsilon_{1}$ & $0.94(0-4 \mu \mathrm{m})$ and $(4 \mu \mathrm{m}-\infty)$ \\
$\varepsilon_{2}, \alpha_{2}$ & 0.9 \\
$\rho_{2}$ & 0.8 \\
\hline \hline
\end{tabular}




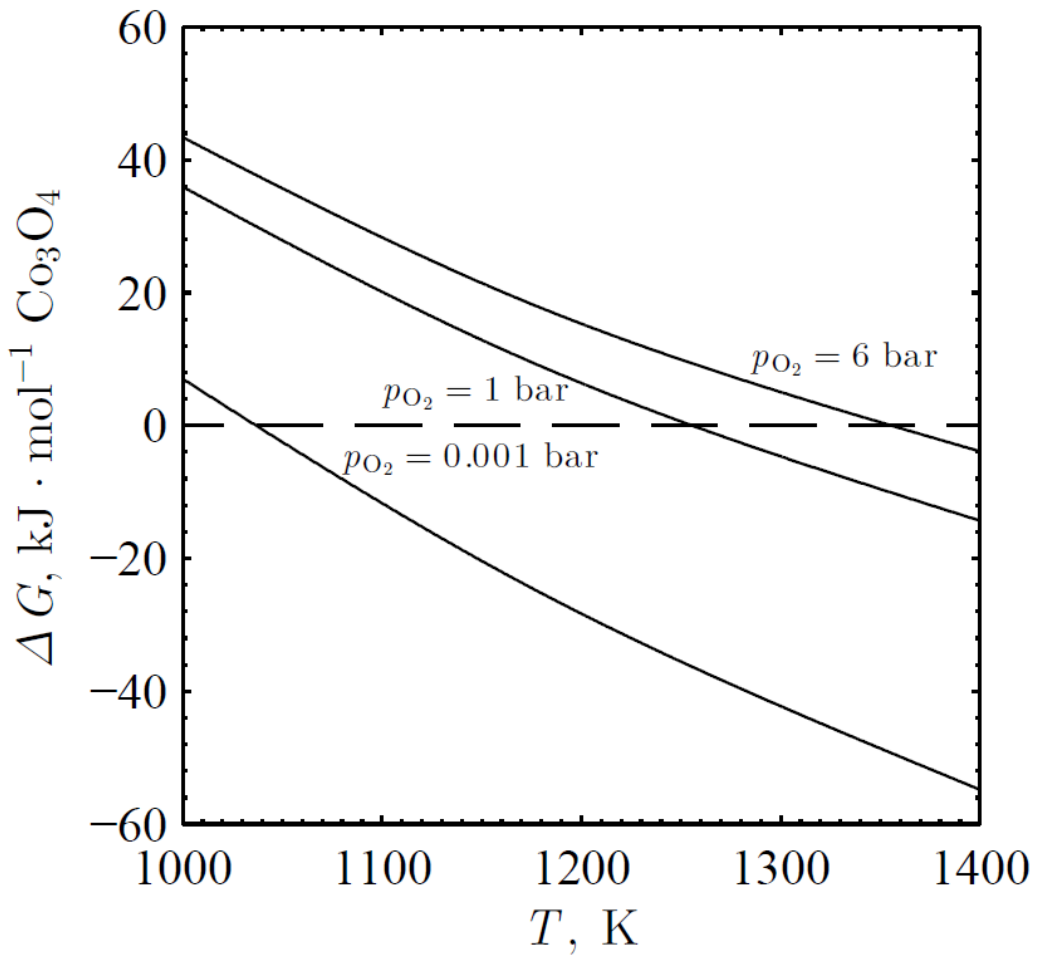

Figure 1. Gibb's free energy function difference for the $\mathrm{Co}_{3} \mathrm{O}_{4} \rightarrow 3 \mathrm{CoO}+1 / 2 \mathrm{O}_{2}$ reaction as a function of temperature at partial $\mathrm{O}_{2}$ pressures of $0.001 \mathrm{bar}, 1 \mathrm{bar}$, and 6 bar.

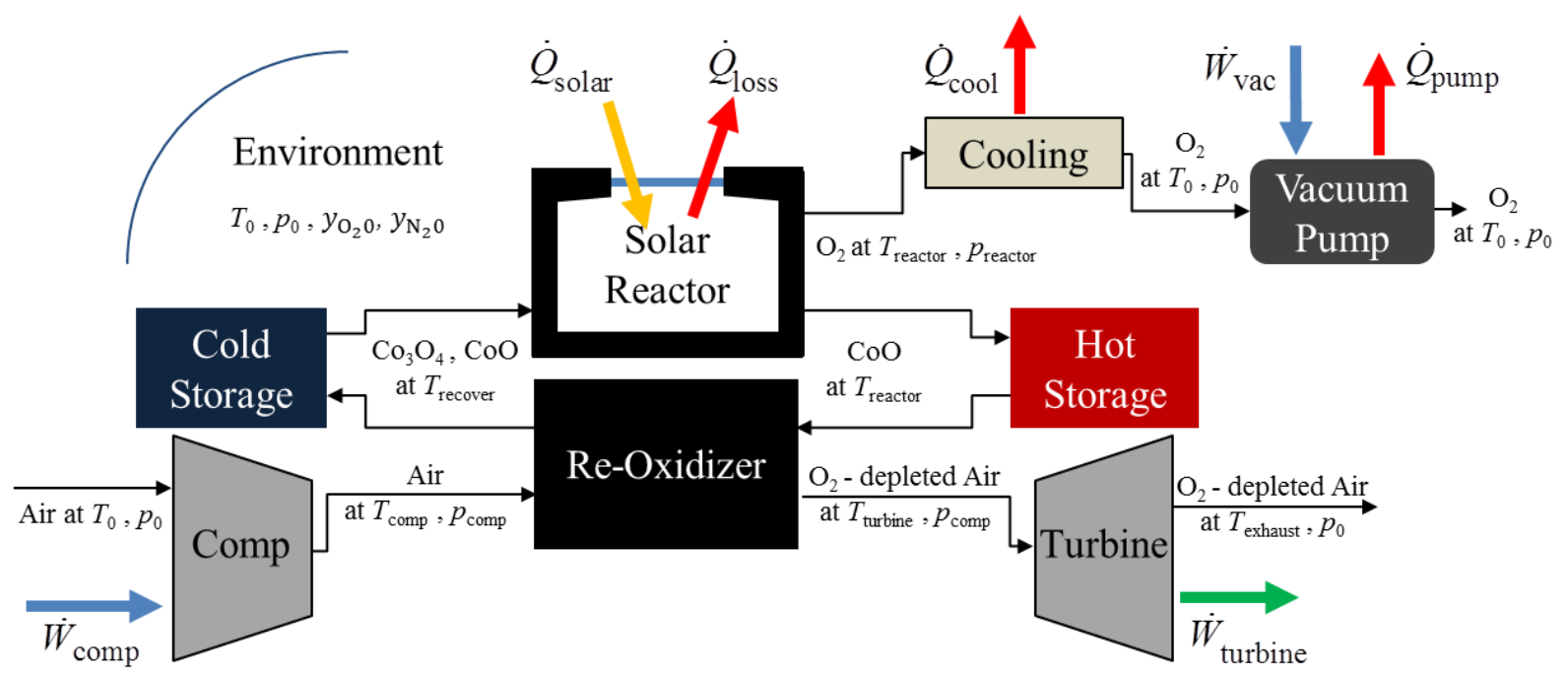

Figure 2. A flow diagram of the Air-Standard Brayton cycle with an integrated two-step solar thermochemical heat storage cycle based on $\mathrm{Co}_{3} \mathrm{O}_{4} / \mathrm{CoO}$ redox reactions is depicted with relevant heat and work flows into and out of the system. 


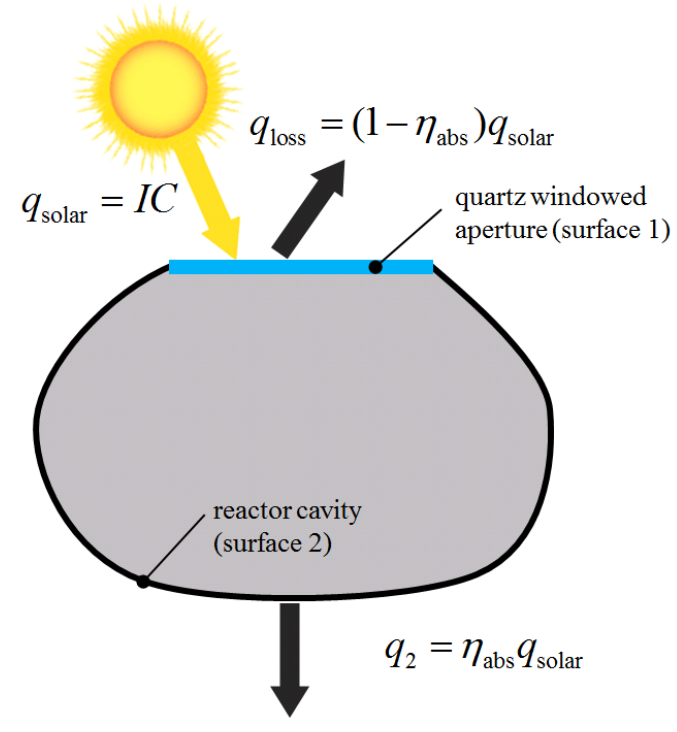

Figure 3. A schematic depiction of a simplified solar thermochemical reactor geometry for radiative exchange analysis between a quartz window (Surface 1) and reactor cavity (Surface 2) with incident concentrated solar irradiation passing through the window and directly impinging on the reactor cavity.

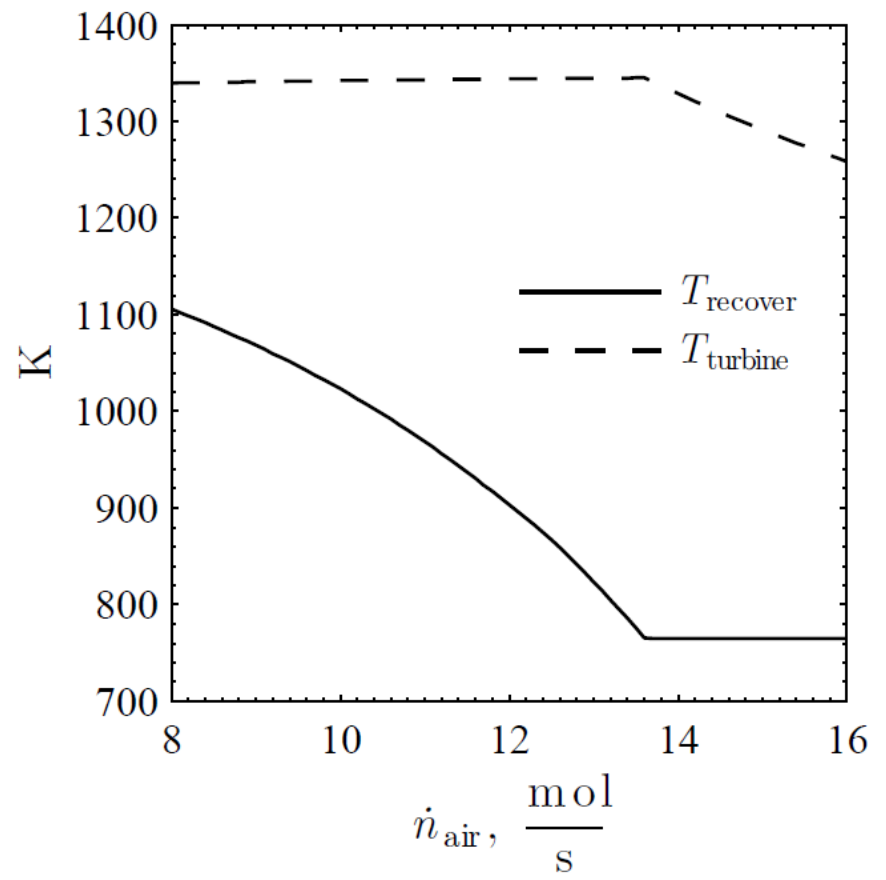

Figure 4. Particle temperature exiting re-oxidizer to the cold storage bin (solid) and air temperature entering turbine from the re-oxidizer (dashed) as functions of molar flow of air exiting the compressor at $30 \mathrm{bar}$ for a solar thermochemical reactor temperature of $1050 \mathrm{~K}$. 


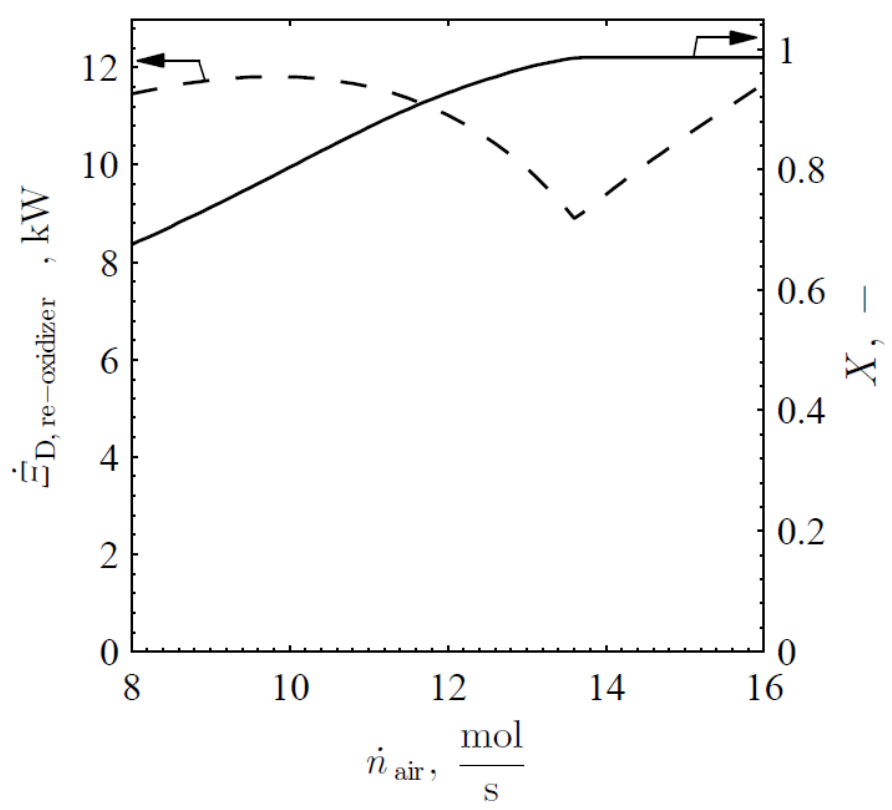

Figure 5. Exergy destruction rate (dashed) and conversion of $\mathrm{CoO}$ to $\mathrm{Co}_{3} \mathrm{O}_{4}$ (solid) across the re-oxidizer as functions of molar flow of air exiting the compressor at 30 bar and solar thermochemical reactor temperature of $1050 \mathrm{~K}$.

(a)

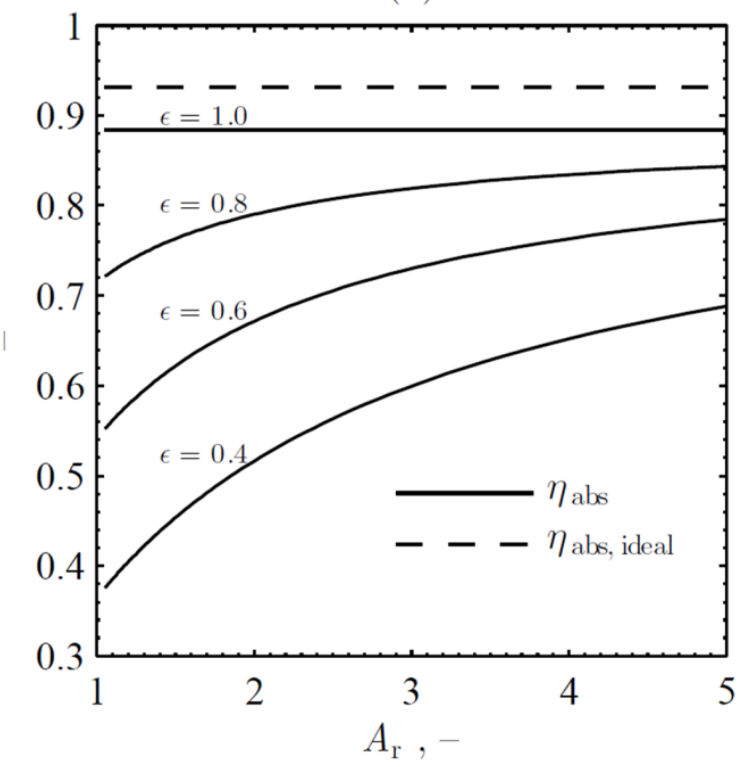

(b)

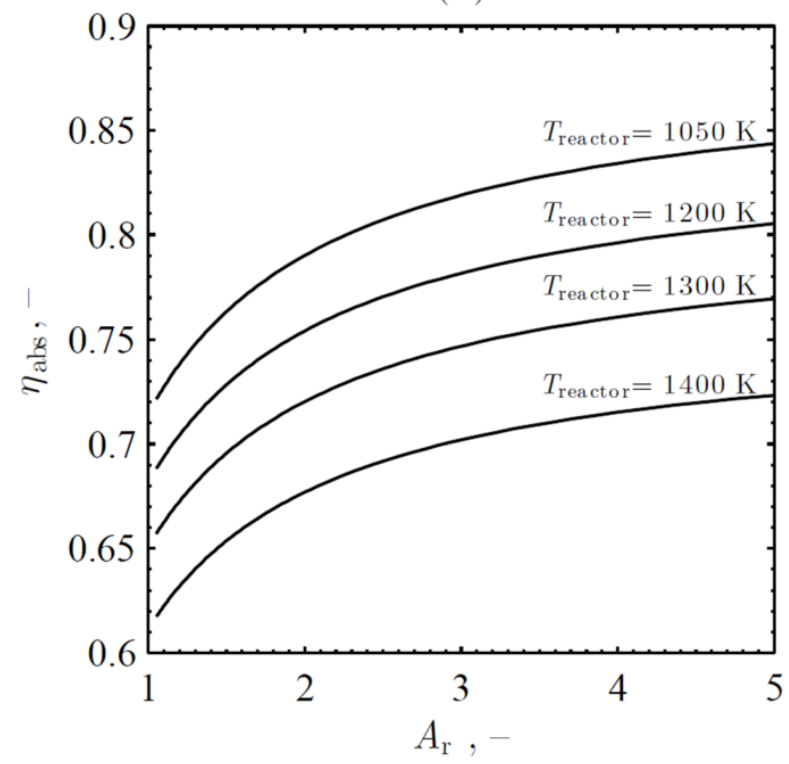

Figure 6. Absorption efficiency versus area ratio between the cavity and the quartz window for a solar thermochemical reactor for (a) a range of cavity emittances (solid) compared to a theoretical blackbody cavity (dashed) at a cavity temperature equal to $1050 \mathrm{~K}$; and (b) a range of cavity temperatures for the cavity emittance equal to 0.8 . 


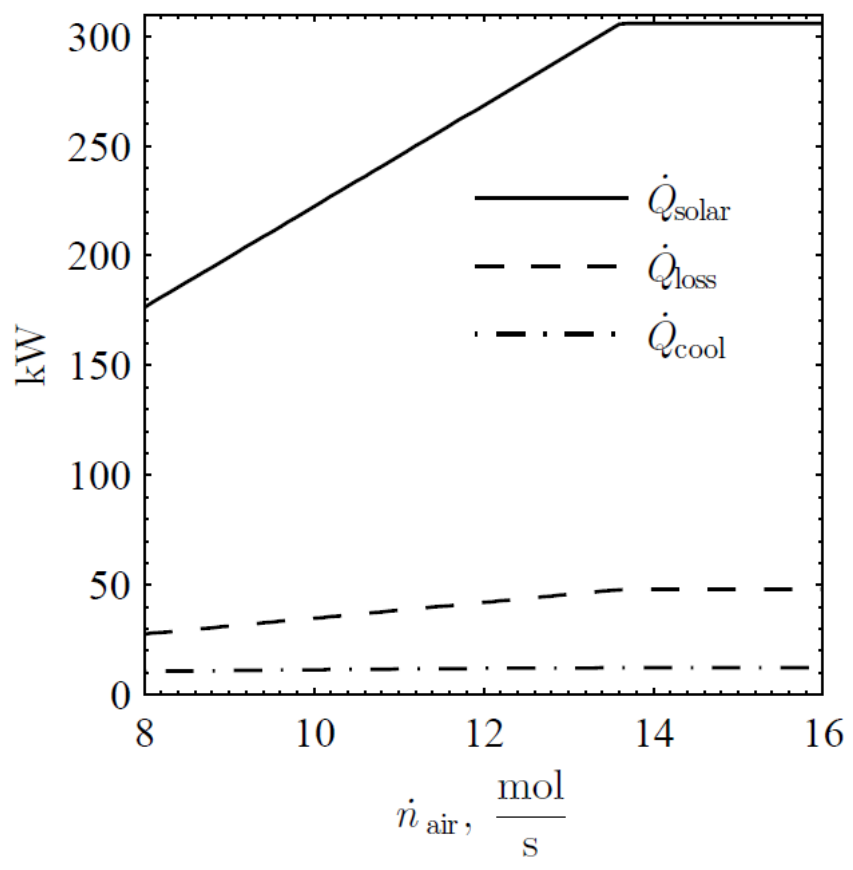

Figure 7. Concentrated solar power input (solid) and heat loss rate to the surrounding (dashed) for the solar thermochemical reactor and the rate of heat rejected to the surroundings from $\mathrm{O}_{2}$ cooling (dash-dot) as functions of the molar flow of air exiting the compressor at 30 bar and a thermochemical reactor temperature of $1050 \mathrm{~K}$.

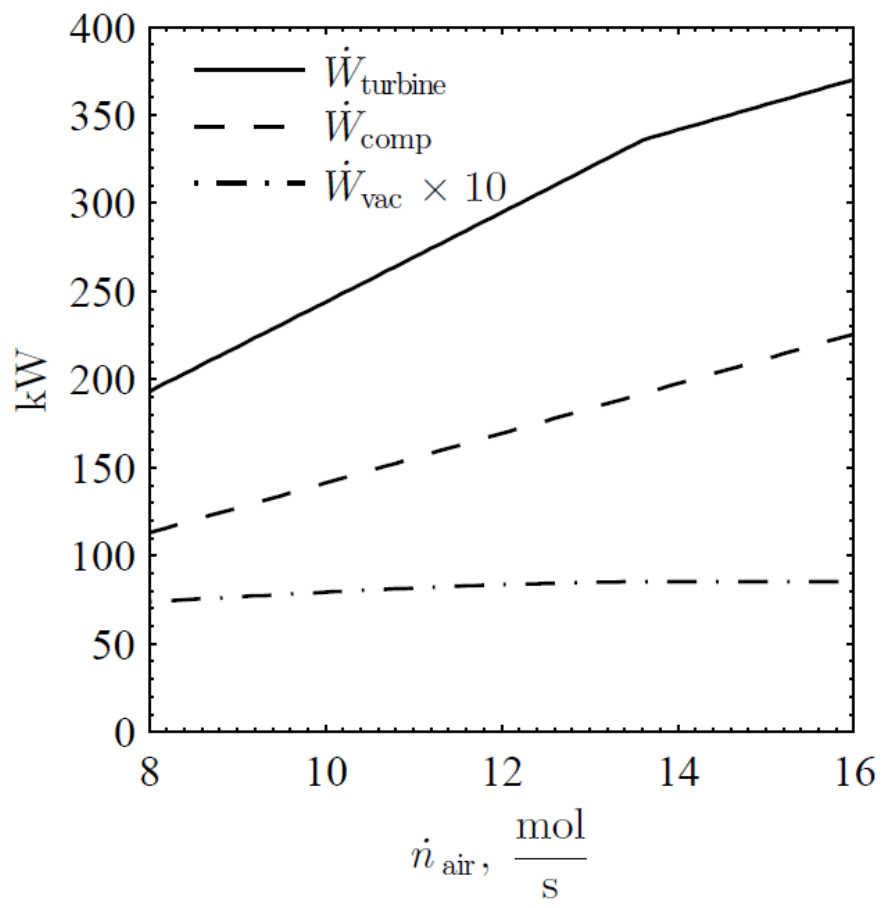

Figure 8. Rates of work for the turbine (solid), compressor (dashed), and vacuum pump (dashdot) as functions of molar flow of air exiting the compressor at 30 bar and a thermochemical reactor temperature of $1050 \mathrm{~K}$. 


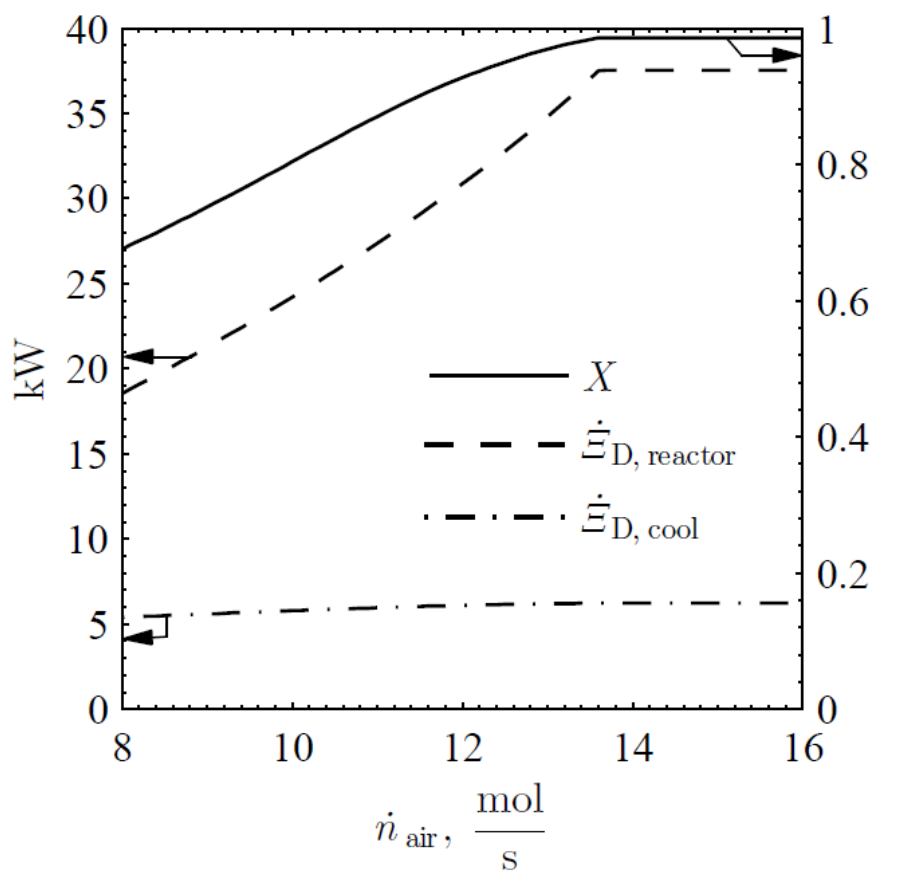

Figure 9. Exergy destruction rates in the solar thermochemical reactor (solid) and quench (dashed) and conversion of $\mathrm{CoO}$ to $\mathrm{Co}_{3} \mathrm{O}_{4}$ in the re-oxidizer (dashed-dotted) as functions of molar flow of air exiting the compressor at 30 bar and a thermochemical reactor temperature of $1050 \mathrm{~K}$.

(a)

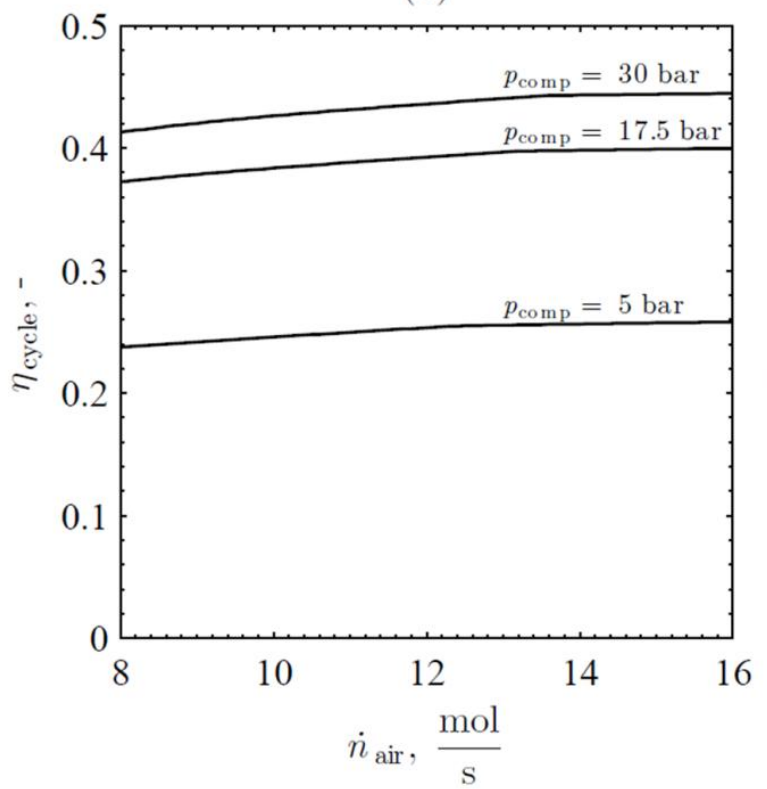

(b)

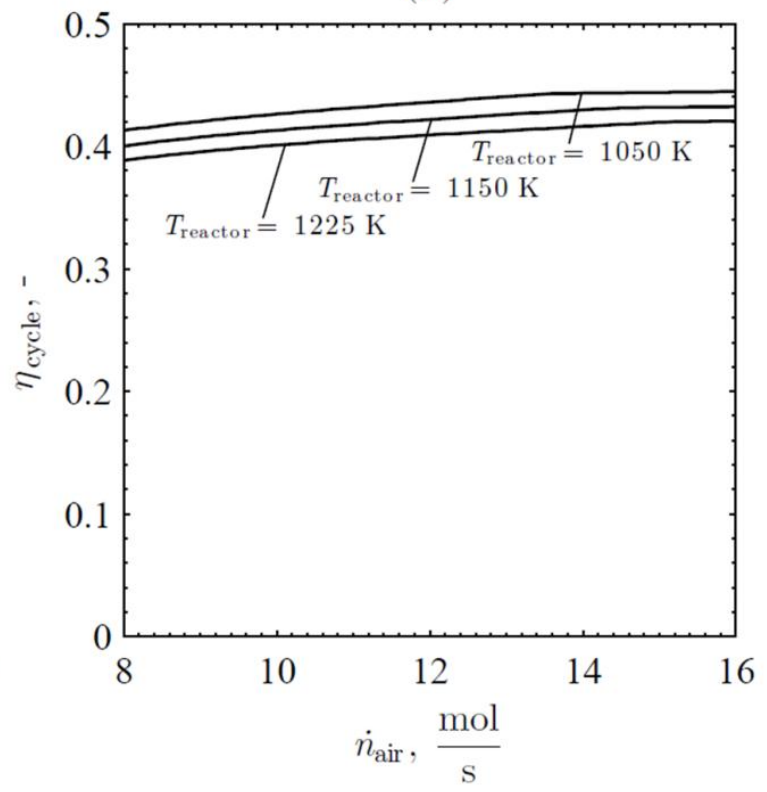

Figure 10. Overall cycle efficiency as a function of molar flow of air exiting the compressor for (a) a range of pressures exiting the compressor between 5-30 bar for solar thermochemical reactor temperature of $1050 \mathrm{~K}$; and (b) a range of solar thermochemical reactor temperatures between $1050-1225 \mathrm{~K}$ for a pressure exiting the compressor of $30 \mathrm{bar}$. 